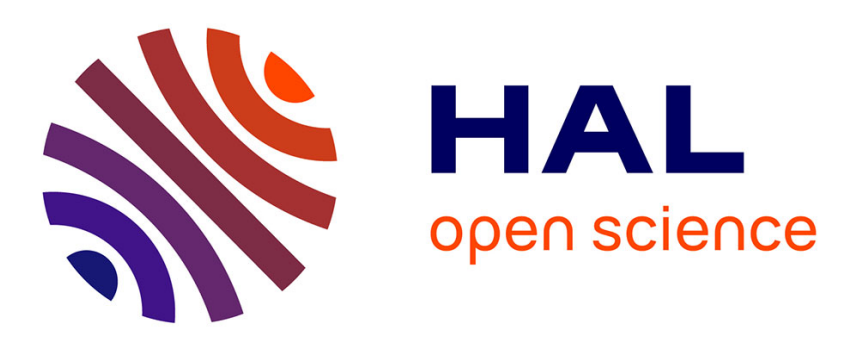

\title{
Nonlinear optical effects in rotationally-twinned crystals: An evaluation of CdTe, ZnTe and ZnSe
}

\author{
C. Forbes Dewey
}

\section{To cite this version:}

C. Forbes Dewey. Nonlinear optical effects in rotationally-twinned crystals: An evaluation of CdTe, ZnTe and ZnSe. Revue de Physique Appliquée, 1977, 12 (2), pp.405-409. 10.1051/rphysap:01977001202040500 . jpa-00244182

\section{HAL Id: jpa-00244182 https://hal.science/jpa-00244182}

Submitted on 1 Jan 1977

HAL is a multi-disciplinary open access archive for the deposit and dissemination of scientific research documents, whether they are published or not. The documents may come from teaching and research institutions in France or abroad, or from public or private research centers.
L'archive ouverte pluridisciplinaire HAL, est destinée au dépôt et à la diffusion de documents scientifiques de niveau recherche, publiés ou non, émanant des établissements d'enseignement et de recherche français ou étrangers, des laboratoires publics ou privés. 


\title{
NONLINEAR OPTICAL EFFECTS IN ROTATIONALLY-TWINNED CRYSTALS : AN EVALUATION OF CdTe, ZnTe AND ZnSe
}

\author{
C. FORBES DEWEY, Jr. \\ Department of Mechanical Engineering Massachusetts Institute of Technology \\ Cambridge, Massachusetts, 02139, U. S. A.
}

\begin{abstract}
Résumé. - Des expériences récentes ont montré que certains effets en optique non linéaire pouvaient être augmentés dans les cristaux $\overline{4} 3 \mathrm{~m}$ comportant des mâcles désorientées les unes par rapport aux autres. Ceci résulte de l'additivité de la puissance optique non linéaire générée dans les divers domaines de l'échantillon. Pour des mâcles espacées au hasard, l'accroissement est proportionnel au nombre de plans de mâcles $N$, alors que si l'espacement est constant la variation suit une loi en $N^{2}$. On discutera les avantages potentiels en optique non linéaire des cristaux de CdTe, $\mathrm{ZnTe}$ et $\mathrm{ZnSe}$ présentant ce type de mâcles. On donnera des critères en vue de déterminer le meilleur espacement des mâcles et on discutera les possibilités d'emploi de ces dispositifs dans divers domaines de l'optique non linéaire.
\end{abstract}

\begin{abstract}
Recent experiments have demonstrated that enhanced nonlinear optical effects may be produced in $\overline{4} 3 \mathrm{~m}$ crystals containing rotational twins. The enhancement arises from addition of the nonlinear optical power generated from different domains of the crystal. For randomlyspaced rotational twins, the enhancement is proportional to the number of twin planes, $N$, and for equally-spaced twin planes the enhancement is proportional to $N^{2}$. A comparison is made between CdTe, $\mathrm{ZnTe}$, and $\mathrm{ZnSe}$ as to their potential usefulness as nonlinear optical crystals emploing rotational twins for phase matching. Criteria for determining optimum twin spacing are given, and applications to various nonlinear optical processes are discussed.
\end{abstract}

1. Introduction. - Nonlinear optical mixing in crystals has proven to be a practical and efficient method of producing fixed-frequency and wavelengthtunable radiation from the ultraviolet to the far infrared region of the spectrum. Typical nonlinear optical processes, as described in standard treatises [1, 2], include frequency doubling, sum- and differencefrequency generation, and parametric oscillation. Kuhl and Schmidt [3] have presented a comprehensive review of various methods for producing tunable coherent radiation, and suggest numerous practical applications for such optical sources.

All transparent crystals exhibit optical dispersion, and hence any nonlinear process involving the production of radiation at one frequency from pumping radiation at a different frequency will involve phase differences between the radiation produced by the induced polarization at different points within the crystal. The conventional method of removing this limitation is to employ nonlinear crystals which are birefringent; by appropriate orientation of the crystal axes and the polarization of the pump beam, it is possible to achieve an exact cancellation of the phase differences caused by dispersion with an opposite phase difference introduced by birefringence. This process is termed phase matching.
Useful phase-matched nonlinear optical crystals must meet four stringent criteria simultaneously :

(i) the crystal must be transparent at the wavelengths of interest,

(ii) it must have large nonlinear optical coefficients,

(iii) the crystal must resist damage at the high power densities required for nonlinear effects,

(iv) it must possess sufficient birefringence to allow phase matching.

Experience of the last decade, particularly by investigators at Bell Telephone Laboratories, Lincoln Laboratories of MIT, C.N.R.S., Stanford, RRE, and the University of Southampton, has demonstrated that it is very difficult to grow birefringent crystals of acceptable size and quality which meet these criteria. Other classes of crystals, such as $\overline{4} 3 \mathrm{~m}$ materials like $\mathrm{CdTe}$ and $\mathrm{ZnSe}$, are not birefringent but have excellent transparency, high nonlinearity, and high damage thresholds.

Several alternative methods of achieving phasematching other than birefringence have been proposed [4-7], following the original suggestions of Bloembergen [8, 9]. Experimental interest in these techniques [10] has been revived in the last several years [11-14] because they promise to be particularly 
useful for producing wavelength-tunable radiation in the infrared.

Recently, we have demonstrated $[15,16]$ that enhanced nonlinear optical effects may be generated in rotationally-twinned crystals. In this paper, the physical basis of these effects will be described and an evaluation of several useful $\overline{4} 3 \mathrm{~m}$ materials will be given.

2. Optical properties of rotationally-Twinned crystals. - As-grown specimens of CdTe and other $\overline{4} 3 \mathrm{~m}$ crystals frequently exhibit numerous rotational twins. Figure 1 is a photograph of a $\mathrm{ZnSe}$ crystal

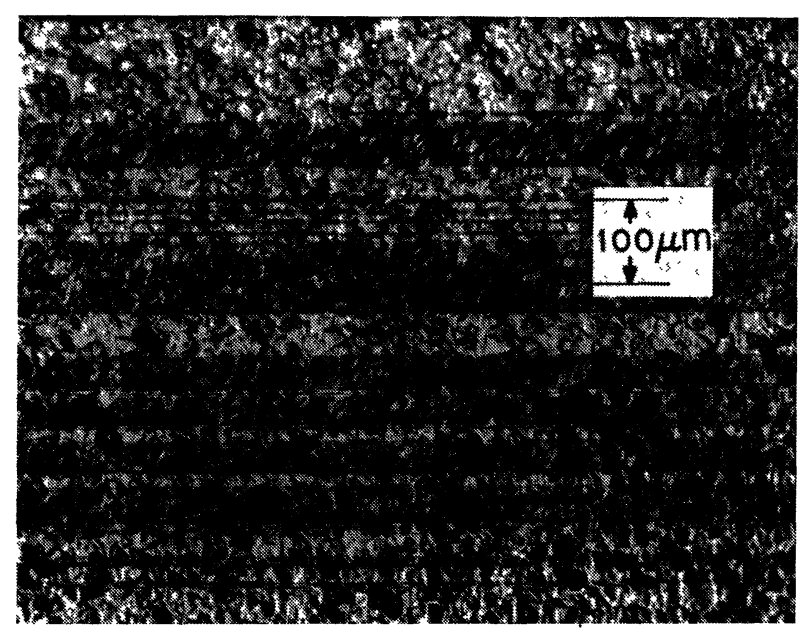

FIG. 1. - Photograph of a specimen of ZnSe illustrating closelyspaced rotational twins. [From DeweY and Hocker, Appl. Phys. Lett. 26 (1975) 442].

exhibiting substantial twinning. $\overline{4} 3 \mathrm{~m}$ crystals have crystallographic orientations such that twin planes are perpendicular to the $\langle 111\rangle$ axis. Figure 2 illustrates the relationship between the individual crystallographic domains in a twinned crystal. The upper diagram is a single crystal domain divided into a series of slabs. If alternate slabs were rotated $60^{\circ}$, as shown in the lower diagram, the crystallographic domains would be equivalent to those of a single crystal with rotational twins separating the domains. The $\overline{43} \mathrm{~m}$ crystal symmetry is such that a $60^{\circ}$ rotation about the $<111>$ axis is equivalent to a rotation of $180^{\circ}$ about an axis perpendicular to the $\langle 111\rangle$ direction. Consequently, the nonlinear optical properties of rotationallytwinned crystals are equivalent to those of the lamellar structures originally proposed by Bloembergen $[8,9]$ for periodic phase matching.

The induced nonlinear polarization may be illustrated coveniently by the use of an Argand diagram (Fig. 3). For a single-domain crystal, figure $3 a$, the amplitude of the radiated electric field arising from nonlinear polarization is proportional to $\sin \theta$, where $\theta \equiv \pi x / l_{c}, x$ is the distance into the crystal along the propagation direction, and $l_{\mathrm{c}}$ is defined as the cohe-
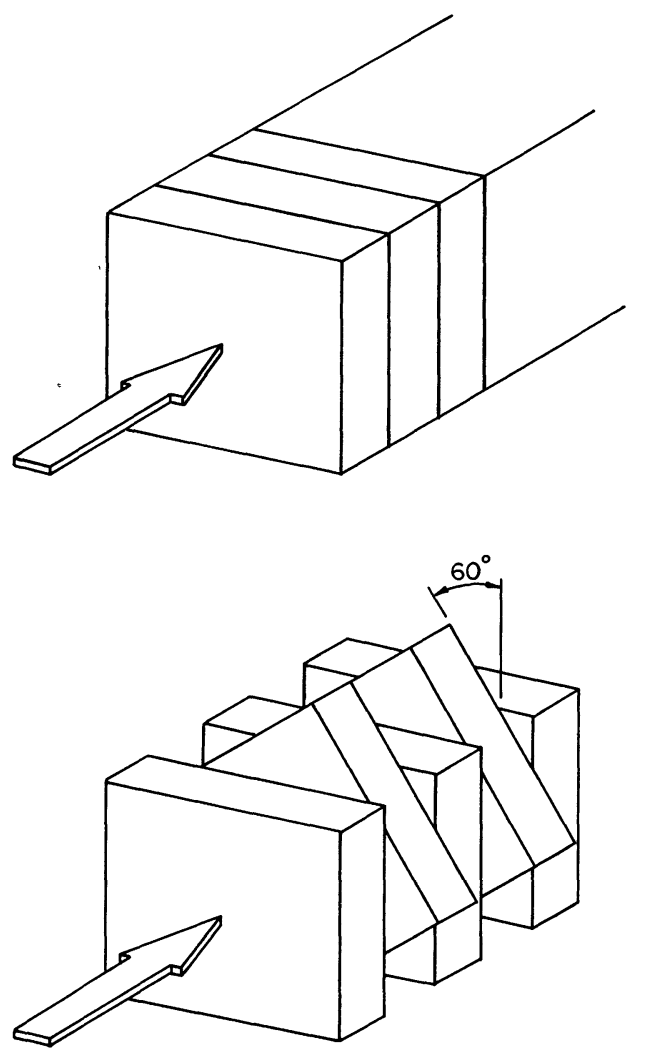

FIG. 2. - Relationship between consecutive crystal domains in a rotationally-twinned crystal.

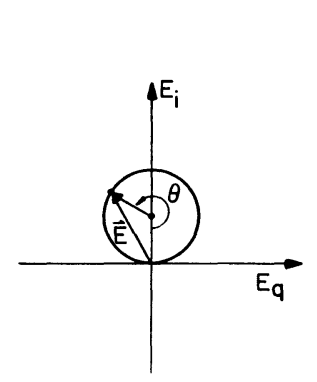

(a)

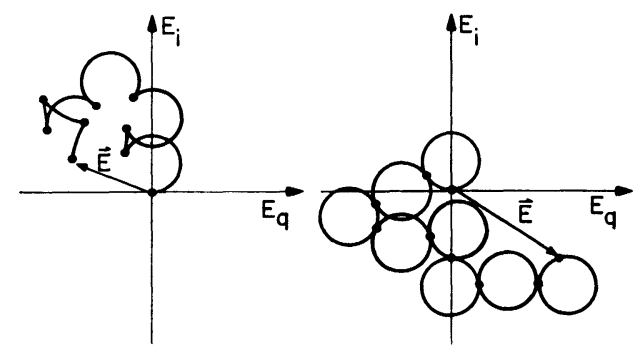

(c)

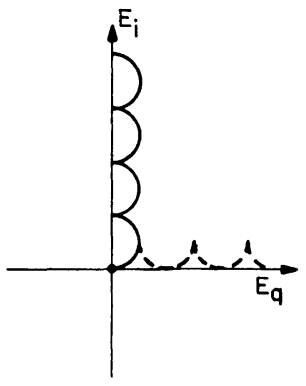

(b)
FIG. 3. - Argand diagram of electric field radiated by induced nonlinear polarization. $E_{\mathrm{i}}$ and $E_{\mathrm{d}}$ are orthogonal components. a) represents a single-domain crystal ; $b$ ) is a crystal with regular twin spacing equal to $l_{\mathrm{c}} ; c$ ) is a crystal with random twin spacing smaller than $l_{\mathrm{c}^{\prime}}$ and $d$ ) is a crystal with random twin spacing larger than $l_{\mathrm{c}}$. [After DewEY and Hocker, Appl. Phys. Lett. 26 (1975) 442.] 
rence length of the nonlinear process. $l_{\mathrm{c}}$ decreases with increasing dispersion, and $l_{\mathrm{c}}$ is typically in the range $1 \mu \mathrm{m}$ to $10^{2} \mu \mathrm{m}$. $E_{\mathrm{i}}$ and $E_{\mathrm{q}}$ are the orthogonal components of the radiated electric field ; the radiated nonlinear optical power is proportional to $|E|^{2}$.

Depending upon the propagation direction and polarization of the pump beam, one or more components of the induced nonlinear polarization will exhibit a reversal of direction at each twin boundary [15]. Figure $3 b$ illustrates the resulting radiated electric field for the case of a regularly-twinned crystal with twin spacing equal to $l_{c}$; the magnitude of $E$ increases in proportion to $l_{\mathrm{c}}$ times the number of domains, $N$, and the nonlinear power increases as $N^{2} l_{\mathrm{c}}^{2}$. For random twin spacings greater than $l_{\mathrm{c}}$, one would expect a random walk process so that the nonlinear optical power would scale approximately as $N l_{\mathrm{c}}^{2}$. This prediction is consistent with our experimental results [15-17].

To illustrate the broad range of potential applications of rotationally-twinned nonlinear optical crystals, I would like to describe briefly three experiments which we have performed. The first [15] was to mix a ruby laser and a ruby-pumped dye laser in $\mathrm{ZnSe}$, producing difference-frequency radiation continuously tunable from $3 \mu \mathrm{m}$ to $21 \mu \mathrm{m}$. The crystal contained approximately 150 randomly-spaced rotational twins with a separation greater than one coherence length. The measured infrared power was 250 times that expected from a single-domain crystal. A second experiment [16], again in $\mathrm{ZnSe}$, used a rubypumped dye laser as the optical pump and yielded tunable second-harmonic generation in the vicinity of $500 \mathrm{~nm}$. An enhancement of 1600 over the singledomain signal was observed. By tuning the fundamental wavelength, it was possible to illustrate the effects of absorption at second-harmonic wavelengths shorter than the bandgap. The thrid experiment [17] was to frequency double a $10 \mu \mathrm{m} \mathrm{CO}_{2}$ laser in CdTe ; the crystal contained 10 rotational twins oriented nearly perpendicular to the direction of propagation of the fundamental. By rotating the crystal, substantial oscillations of the second-harmonic output, analogous to the Maker fringes observed in a single-domain crystal, could be observed. The peak second-harmonic power was approximately 42 times that of a singledomain crystal, or 1.7 times that obtained with 5 oriented plates [14].

The results cited in the previous paragraph pertain to crystals in which the twin spacings of the as-grown crystals were essentially random. Clearly, much more favorable results could be obtained if the mechanisms of twin formation were sufficiently well understood to allow the growth of crystals with regular twin spacings.

3. Growth of rotationally-twinned crystals. - In the past, crystal growers have viewed rotational twins as undesireable defects, and conditions were sought which minimized their occurence. Archival publications on various growth methods generally report only the conditions which yield twin-free specimens, with scant information on the causes of twinning. In CdTe, Zanio [18] has observed twinning in large CdTe crystals grown by the Czochralski method, by the Bridgman-Stockbarger technique, and by vapor transport. The frequency of twinning in the vapor-grown crystals was influenced by radial temperature gradients in the condensed phase. Richman [19] observed twinning in gradient freeze growth of InP which was attributed to excess In concentration. During liquid-encapsulation Czochralski growth of InP, Bachmann et al. [20] found twins to occur when small gas bubbles were entrapped between the $\mathrm{B}_{2} \mathrm{O}_{3}$ encapsulation melt and the InP melt, causing local asymmetry of the radial heat flux. De Nobel [21], in his classic paper on the growth of CdTe by zone melting, observed frequent twinning in crystals obtained with that method, although no mechanism of twin formation was identified. InSb-GaSb crystals grown in a gravity field and also in the Skylab experiment exhibited substantial twinning [22]. GaSb and InAs reveal a growth structure in which the favored direction of growth is strongly influenced by the presence of twins [23]. Rapid growth can occur in the direction of the twin plane by the twin plane reentrant edge (TPRE) growth mechanism. Thus, twinned seed crystals of materials exhibiting TPRE could be grown to larger dimension. The relations between twin plane orientation and growth for Czochralski-grown InSb have been discussed by Miller and Witt [24].

\section{Comparison of crystals for non-linear optical} applications. - Table $\mathrm{I}$ is a compilation of properties of selected crystals useful for nonlinear optical applications in the infrared. Included in the list are birefringent phase-matchable crystals as well as nonbirefringent $43 \mathrm{~m}$ materials which may be employed in periodic phase matching schemes. The data were compiled from a number of sources, including the surveys by Kurtz [25, 26], Byer [27], and Akhmanov et al. [28], the book by Zernike and Midwinter [2], nonlinear coefficients for $\mathrm{GaAs}$ and $\mathrm{CdTe}$ as adopted by Thompson et al. [13] and Piltch et al. [14], respectively, data on InAs and GaSb from Wynne and Bloembergen [29], and unpublished data we have obtained on damage thresholds for proustite $\left(\mathrm{Ag}_{3} \mathrm{AsS}_{3}\right)$ and $\mathrm{ZnSe}$.

The $\overline{4} 3 \mathrm{~m}$ materials, in general, have larger regions of transparency, larger nonlinear optical coefficients, and larger damage thresholds than birefringent crystals. In addition, they-may be grown easily, exhibit very low absorption coefficients, and possess excellent homogeneity. Although $\mathrm{CdGeAs}_{2}$ has a very large figure of merit, $d_{\mathrm{eff}}^{2} / n^{3}$, and is phase-matchable, the number of optically useful crystals which have been grown over the past three years is very small in spite of substantial efforts by several leading laboratories. The absorption 
TABLE I

Properties of selected infrared nonlinear crystals

\begin{tabular}{|c|c|c|c|c|c|c|c|}
\hline & $\begin{array}{l}\text { Crystal } \\
\text { class }\end{array}$ & $\begin{array}{c}\text { Transparency } \\
(\mu \mathrm{m})\end{array}$ & $\begin{array}{c}d_{i j} \times 10^{12} \\
(\mathrm{~m} / \mathrm{V})\end{array}$ & $n$ & $\begin{array}{c}\left(d_{\mathrm{eff} f}^{2} / h^{3}\right) \times 10^{24} \\
\left(\mathrm{~m}^{2} / \mathrm{V}^{2}\right)\end{array}$ & $\begin{array}{c}l_{\mathrm{c}}(\mu \mathrm{m}) \\
10.6 \mu \mathrm{m} \rightarrow 5.3 \mu \mathrm{m}\end{array}$ & $\begin{array}{l}\text { Damage } \\
\text { threshold } \\
\text { (MW/cm² }\end{array}$ \\
\hline \multicolumn{8}{|l|}{ Birefringent } \\
\hline $\mathrm{Ag}_{3} \mathrm{~A}_{\mathbf{s}} \mathrm{S}_{3}$ & $3 m\left(C_{3 v}\right)$ & $0.6-12.5$ & 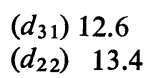 & $\begin{array}{l}n_{0}=2.83 \\
n_{\mathrm{e}}=2.60\end{array}$ & 10 & - & $5-20$ \\
\hline $\mathrm{AgGaS}_{2}$ & $\overline{4} 2 \mathrm{~m}$ & $0.6-13$ & $\left(d_{36}\right) \quad 18$ & $\begin{array}{l}n_{0}=2.42 \\
n_{\mathrm{e}}=2.24\end{array}$ & 30 & - & $12-25$ \\
\hline $\mathrm{AgGaSe}_{2}$ & $\overline{4} 2 \mathrm{~m}$ & $0.73-17$ & $\left(d_{36}\right) \quad 33$ & $\begin{array}{l}n_{0}=2.62 \\
n_{\mathrm{e}}=2.58\end{array}$ & 50 & - & $>10$ \\
\hline $\mathrm{HgS}$ & $32\left(d_{3}\right)$ & $0.65-15$ & $\left(d_{11}\right) \quad 57$ & $\begin{array}{l}n_{0}=2.70 \\
n_{\mathrm{e}}=2.99\end{array}$ & 120 & - & $>5$ \\
\hline $\mathrm{CdGeAs}_{2}$ & $\overline{4} 2 \mathrm{~m}$ & $2.4-17$ & $\left(d_{36}\right) 236$ & $\begin{array}{l}n_{0}=3.51 \\
n_{\mathrm{e}}=3.59\end{array}$ & 1020 & - & $20-40$ \\
\hline \multicolumn{8}{|c|}{ Non-birefringent } \\
\hline CdTe & $\overline{4} 3 \mathrm{~m}$ & $0.9-31$ & $\left(d_{14}\right) \quad 60$ & 2.70 & 85 & 186 & 100 \\
\hline $\mathrm{ZnSe}$ & $\overline{4} 3 \mathrm{~m}$ & $0.5-22$ & $\left(d_{14}\right) 73$ & 2.42 & 170 & 100 & $>100$ \\
\hline $\mathrm{ZnTe}$ & $\overline{4} 3 \mathrm{~m}$ & $0.6-52$ & $\left(d_{14}\right) \quad 94$ & 2.69 & 210 & 290 & (High) \\
\hline GaAs & $\overline{4} 3 \mathrm{~m}$ & $1.5-17$ & $\left(d_{14}\right) 150$ & 3.29 & 295 & 105 & 100 \\
\hline InAs & $\overline{4} 3 \mathrm{~m}$ & 4-22 & $\left(d_{14}\right) 420$ & 3.5 & 645 & 53 & $?$ \\
\hline GaSb & $\overline{4} 3 \mathrm{~m}$ & $2-20$ & $\left(d_{14}\right) 630$ & 3.8 & 1135 & 134 & $?$ \\
\hline
\end{tabular}

coefficient of $\mathrm{CdGeAs}$ ranges from $0.1-1.0 \mathrm{~cm}^{-1}$ even in the useful crystals, whereas $\mathrm{CdTe}, \mathrm{ZnSe}$, and GaAs routinely exhibit bulk absorption coefficients in the ranges of $10^{-3}-10^{-4} \mathrm{~cm}^{-1}$.

$\mathrm{CdTe}$ and $\mathrm{ZnSe}$ are notable for their propensity to exhibit rotational twinning during growth. We have examined numerous CdTe crystals having a mean twin spacing of about $1 \mathrm{~mm}$. This spacing is considerably larger than the $100 \mu \mathrm{m}$ coherence length for doubling a $10.6 \mu \mathrm{m}$ laser. A $1 \mathrm{~cm}$ long crystal of CdTe with 22 regularly-spaced twin planes (each $3 l_{\mathrm{c}}$ long) would produce better than $20 \%$ conversion to $5.3 \mu \mathrm{m}$ second-harmonic radiation at an internal fundamental power density of $100 \mathrm{MW} / \mathrm{cm}^{2}$ [14].

A figure of merit for comparing rotationally-twinned or lamellar structures may be derived from theory (e. g. Ref. [2]). Let us take second-harmonic generation as a typical nonlinear process. If each domain is an odd number of coherence lengths long, then, in mixed units [14], second-harmonic generation is described by

$$
\frac{P(2 \omega)}{P(\omega)}=\frac{1.21 \times 10^{8} d_{\mathrm{eff}}^{2} P(\omega) l_{\mathrm{c}}^{2}}{n(\omega)^{2} n(2 \omega) \lambda(\omega)^{2}} .
$$

where $\left[d_{\text {eff }}\right]=(\mathrm{m} / \mathrm{V}), \quad[P]=\left(\mathrm{W} / \mathrm{cm}^{2}\right),(*), \quad$ and $\left[l_{\mathrm{c}}, \lambda\right]=(\mathrm{cm})$. Second-harmonic generation efficiency is therefore proportional to $\left[d_{\mathrm{eff}}^{2} l_{\mathrm{c}}^{2} / n^{3}\right]$, a term which is an appropriate figure of merit for this process. For $N$

$\left({ }^{*}\right)$ Note that $P(\omega)$ is the fundamental power inside the crystal. If the pump is incident on the crystal at Brewster's angle, $\theta_{\mathrm{B}}=\tan ^{-1} n$, then the beam cross-section inside the crystal is larger by a factor of $n$ and the power density is reduced by a factor of $n$ from that of the incident beam. regular domains, the fractional conversion is $N^{2}$ times as large.

The effective nonlinear coefficient, $d_{\text {eff }}$, depends upon the orientation of the crystal axes with respect to the direction of propagation and polarization of the pump beam. If the pump propagates along the $<111>$ axis in a $\overline{4} 3 \mathrm{~m}$ crystal, the effective nonlinear coefficient [11] is $(2 / 3)^{1 / 2} d_{14}$, and these values of $d_{\text {eff }} / n^{3}$ are listed in table I. For birefringent phase-matchable crystals, $d_{\text {eff }}$ depends upon the crystal orientation in a more complicated way (see Kurtz [26]). The values of $d_{\text {eff }}^{2} / n^{3}$ are for crystal orientations yielding the largest $d_{\text {eff }}$ for $10.6 \mu \mathrm{m}$ doubling.

For the six $\overline{4} 3 \mathrm{~m}$ materials listed in table $I$, the relative values of $\left(d_{\mathrm{eff}}^{2} l_{\mathrm{c}}^{2} / n^{3}\right)$ are approximately as follows :

$$
\begin{gathered}
\text { ZnSe }: \text { InAs : CdTe : GaAs : ZnTe : GaSb } \\
1.0: 1.1: 1.7: 1.9: 10.5: 12.0
\end{gathered}
$$

Recognize that the nonlinear coefficients for some of these materials are not known accurately; the relative values listed above are only approximate.

In view of the recent success achieved in frequencydoubling infrared lasers with stacks of oriented singledomain plates $[11,13,14]$, it is useful to consider methods whereby rotationally-twinned crystals could be used to obtain multiple coherent domains in a single crystal. Figure 4 illustrates three possibilities which are currently being investigated in our laboratory. In the first configuration, a crystal containing an isolated twin is cut such that the two domains $a$ on either side of the twin are exactly $M l_{\mathrm{c}}$ in width, where $M$ is an odd integer. The resulting crystal would then be equivalent to two oriented and opti- 
(1)
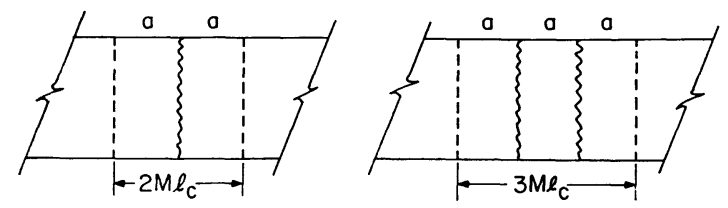

(3)

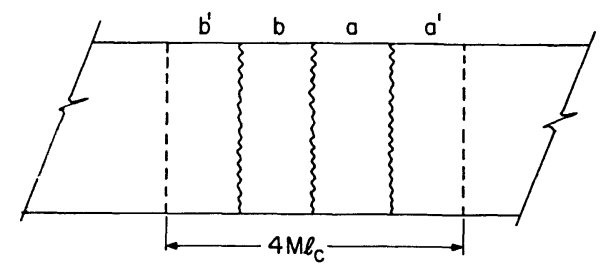

Fig. 4. - Methods of manufacturing crystals with 2, 3 and 4 coherent domains separated by rotational twins.

cally-contacted single-domain plates. The second diagram illustrates a specimen with two isolated twins spaced an odd number $M$ of coherence lengths apart. By cutting the crystal along the dotted lines, a plate with three coherent domains is obtained. (It is possible to propagate the fundamental beam through the crystal at an angle such that the distance $a$ is equal to an odd number of coherence lengths.) The third diagram suggests that if three adjacent twins define two domains, with each approximately an odd number of coherence lengths thick, the crystal may be cut such that the domains $b^{\prime}$ and $a^{\prime}$ are complementary to $b$ and $a$ and coherent addition of the radiated electric field will result. Each such crystal would therefore produce nearly 16 times the nonlinear optical power of a single-domain element. The thickness of fourdomain specimens would be sufficiently large to allow optical contacting [11] between specimens, to achieve composites of $4,8,12,16, \ldots$ coherent domains.

5. Conclusions. - Considerable research remains before it is possible to grow nonlinear crystals with regularly-spaced rotational twins. Useful results have already been achieved with crystals containing many randomly-spaced twins. It is possible to construct composites of plates, each containing four coherent domains, by optical contacting to achieve periodic structures which will yield high efficiencies in applications such a frequency doubling and sum- and difference-frequency generation.

Acknowledgements. - L. O. Hocker has been a principal contributor to the experimental work of our laboratory in this research program. A. Szilagyi is currently investigating the concepts described in figure 4 , and is carrying out a theoretical investigation of randomly-twinned crystals. The development of these concepts has benefitted from discussions with numerous individuals, including L. Shiozawa of Cleveland Crystal, A. Witt and J. W. Cahn of MIT, C. D. Cantrell III and M. Piltch of Los Alamos Scientific Laboratory, J. J. Wynne of IBM Watson Research Laboratory, and N. Bloembergen of Harvard University.

This research has been supported by the Advanced Research Projects Agency and by the Energy Research and Development Administration.

\section{References}

[1] Bloembergen, N., Nonlinear optics (W. A. Benjamin, Inc., N. Y.) 1965.

[2] Zernike, F. and Midwinter, J. E., Appliednonlinear optics, (Wiley and Sons, N. Y.) 1973.

[3] Kunl, J. and Schmid, W., Appl. Phys. 3 (1974) 251-270.

[4] TANG, C. L. and BEY, P. P., IEEE J. Quantum Elect. QE-9 (1973) 9.

[5] Somlexh, S. and Yariv, A., Opt. Commun. 6 (1972) 301.

[6] Yacoby, Y., Aggarwal, R. L. and Lax, B., J. Appl. Phys. 44 (1973) 3180.

[7] Miller, R. C., Phys. Rev. 134 (1964) A 1313.

[8] Armstrong, J. A., Bloembergen, N., Ducuing, J. and Pershan, P. S., Phys. Rev. 127 (1962) 1918.

[9] Bloembergen, N., U. S. Patent No. 3, 384, 433 (1968).

[10] Boyd, G. D. and Patel, C. K. N., Appl. Phys. Lett. 8 (1966) 313.

[11] Szilagyi, A., Hordvik, A. and Schlossberg, H., J. Appl. Phys. 47 (1976) 2025.

[12] VAN DER ZIEL, J. P., IEEE J. Quantum Elect. QE-12 (1976) 407.

[13] Thompson, D. E., McMullen, J. D. and Anderson, D. B., Appl. Phys. Lett. 29 (1976) 113.

[14] Piltch, M. S., Cantrell, C. D. III and Sze, R. D., J. Appl. Phys. 47 (1976) 3514.

[15] Dewey, C. F. Jr. and Hocker, L. O., Appl. Phys. Lett. 26 (1975) 442

[16] Hocker, L. O. and Dewey, C. F. Jr., Appl. Phys. Lett. 28 (1976) 267.

[17] Dewey, C. F. Jr., Hocker, L. O., Piltch, M. S., Barnes, N. F. and CANTRELL, C. D. III, Efficient Infrared Frequency
Doubling and Mixing in Rotationally-Twinned CdTe, unpublished 1976.

[18] ZANIO, K., Hughes Research Laboratories, Malibu, California, U. S. A., private communication.

[19] Richman, D., in Compound Semiconductors, Vol. 1 (R. K. Willardson and H. L. Goering, Eds.) (Reinhold Publ., N. Y.) 1962, pp. 214 et seq.

[20] Bachmann, K. J., Buehler, E., Shay, J. L. and Strnan, A. R., J. Electron. Mat. 4 (1975) 389.

[21] De Nobel, D., Philips Res. Repts. 14 (1959) 361.

[22] Yee, J. F., LiN, M.-C., SARMa, K. and Wilcox, W. R., J. Crystal Growth 30 (1975) 185.

[23] Faust, J. W. Jr., and John, H. F., J. Phys. Chem. Solids 25 (1964) 1407.

[24] Miller, D. C. and WitT, A. F., J. Crystal Growth 29(1975) 19.

[25] KurTz, S. K., in Laser Handbook (North Holland Publ., Amsterdam) 1972, pp. 942 et seq.

[26] Kurtz, S. K., in Quantum Electronics (Vol. I, Part A : Nonlinear Optics) (H. Rabin and C. L. Tang, Ed.) (Academic Press, N. Y.) 1974, pp. 209-281.

[27] Byer, R. L., in Quantum Electronics (Vol. I, Part B : Nonlinear Optics) (H. Rabin and C. L. Tang, Ed.) (Academic Press, N. Y.) 1974, pp. 587-702.

[28] Akhmanov, S. A., Korrygin, A. I. and Sukhorukov, A. P., in Quantum Electronics (Vol. I, Part B: Nonlinear Optics) (H. Rabin and C. L. Tang, Ed.) (Academic Press, N. Y.) 1974. pp. 475-586.

[29] Wynne, J. J. and Bloembergen, N., Phys. Rev. 188 (1969) 1211. 